\title{
Risk Factors and Treatment for Hemorrhage after Pancreaticoduodenectomy: A Case Series of 423 Patients
}

\author{
Feng Gao, ${ }^{1}$ Jianguo Li, ${ }^{2,3}$ Shengwei Quan, ${ }^{1,4}$ Fujun Li, ${ }^{1}$ Donglai Ma, \\ Lei Yao, ${ }^{1}$ and Ping Zhang ${ }^{2}$ \\ ${ }^{1}$ Department of General Surgery, Second Affiliated Hospital of Harbin Medical University, Harbin 150000, China \\ ${ }^{2}$ Department of General Surgery, First Affiliated Hospital of Jilin University, Changchun 130000, China \\ ${ }^{3}$ Department of General Surgery, Heilongjiang Province Hospital, Harbin 150000, China \\ ${ }^{4}$ Department of General Surgery, Heilongjiang Province Land Reclamation Headquarters General Hospital, Harbin 150000, China
}

Correspondence should be addressed to Lei Yao; gf9777@126.com and Ping Zhang; azhangpinga@126.com

Received 3 August 2016; Accepted 19 October 2016

Academic Editor: Dirk Stippel

Copyright (c) 2016 Feng Gao et al. This is an open access article distributed under the Creative Commons Attribution License, which permits unrestricted use, distribution, and reproduction in any medium, provided the original work is properly cited.

\begin{abstract}
The study aimed to investigate the risk factors of postpancreatectomy hemorrhage (PPH) after pancreaticoduodenectomy (PD). A retrospective analysis of 423 patients who underwent PD between January 2008 and January 2014 was conducted. The overall incidence and all-cause mortality of PPH were 9.9\% (42/423) and 2.1\% (9/423), respectively. Independent risk factors of early PPH were revascularization (odds ratio $(\mathrm{OR})=6.786$; $95 \%$ confidence interval $(95 \% \mathrm{CI}): 1.785-25.792 ; P=0.005)$, history of abdominal surgery $(\mathrm{OR}=5.009 ; 95 \% \mathrm{CI}: 1.968-12.749 ; P=0.001)$, and preoperative albumin levels $(\mathrm{OR}=4.863 ; 95 \% \mathrm{CI}: 1.962-12.005 ; P=$ 0.001). Independent risk factors of late PPH included postoperative pancreatic leakage (OR = 4.696; 95\% CI: 1.605-13.740; $P=$ $0.005)$, postoperative biliary fistula $(\mathrm{OR}=6.096 ; 95 \% \mathrm{CI}: 1.575-23.598 ; P=0.009)$, postoperative abdominal infection $(\mathrm{OR}=4.605$; 95\% CI: 1.108-19.144; $P=0.036$ ), revascularization ( $\mathrm{OR}=9.943$; 95\% CI: 1.900-52.042; $P=0.007$ ), history of abdominal surgery $(\mathrm{OR}=8.790 ; 95 \% \mathrm{CI}: 2.779-27.806 ; P<0.001)$, and preoperative albumin levels $(\mathrm{OR}=5.563 ; 95 \%$ CI: $1.845-16.776 ; P=0.002)$.
\end{abstract}

\section{Introduction}

Pancreaticoduodenectomy (PD) is a complex procedure involving extensive resection with significant risk of postoperative complication such as pancreatic and biliary fistula, delayed gastric emptying, abscess formation, and postpancreatectomy hemorrhage (PPH) [1]. Despite improvements in surgical approaches, the rate of complications remains high at $30-50 \%$ and the mortality is still significant, even in high volume centers [1-4].

Due to vast improvements in care in the last decades, the incidence of $\mathrm{PPH}$ is relatively low at $3-10 \%$ but nevertheless has a high mortality rate at $20-50 \%[1,5-17]$. Therefore, when $\mathrm{PPH}$ occurs, it has to be considered a life-threatening condition. In addition, there is no consensus or guideline about the management of $\mathrm{PPH}$, and the reported clinical experience is limited [18, 19]. In 2005 and 2007, the International Study
Group on Pancreatic Fistula (ISPGF) proposed a consensus about pancreatic fistulae [20] and PPH [17]. It emphasizes that a clear definition of PPH and its risk factors is still lacking [17].

PPH may occur either early or late. Early PPH is usually iatrogenic and results from arterial injury or suboptimal hemostasis $[7,8,21,22]$. Early PPH usually requires emergency reoperation. On the other hand, late $\mathrm{PPH}$ is usually a complication of pancreatic fistula or abdominal abscess $[10,13,23]$ and is assessed and treated using angiography and endoscopy. Nevertheless, the prognosis of $\mathrm{PPH}$ remains poor despite advances in imaging and treatment, and no preventive measure is recognized [1].

Therefore, identifying patients who are at higher risk of PPH is clinically relevant. The aim of this study was to review retrospectively the clinical data of 423 patients who underwent PD at a single center and to identify risk factors of $\mathrm{PPH}$. 


\section{Materials and Methods}

2.1. Patients. Between January 2008 and January 2014, 423 patients underwent PD at the Second Affiliated Hospital of Harbin Medical Science University. Inclusion criteria were (1) diagnoses of ampullary cancer, distal cholangiocarcinoma, duodenal adenocarcinoma, pancreatic cancer, partial benign pancreaticoduodenal tumor, chronic pancreatitis, and/or invasion of other tumors into the head of the pancreas and duodenum, as confirmed prior to surgery; (2) PD performed and diagnoses confirmed by pathological examination; (3) $<75$ years old; (4) normal cardiopulmonary functions and coagulation tests; and (5) adequate liver function: total bilirubin $<200 \mu \mathrm{mol} / \mathrm{L}$ and albumin $>30 \mathrm{~g} / \mathrm{L}$. Exclusion criteria were (1) distant metastasis confirmed by imaging or (2) loss to follow-up. Indications for PD were (1) confirmed diagnosis of pancreatic lesions for which $\mathrm{PD}$ was the first treatment choice; (2) early detection and good physical status without distant metastasis; (3) age <75 years old; (4) normal cardiopulmonary functions and coagulation; (5) adequate liver function prior to surgery: total bilirubin $<200 \mu \mathrm{mol} / \mathrm{L}$ and albumin $>30 \mathrm{~g} / \mathrm{L}$; and (6) no tumor invasion of a surrounding major blood vessels. For patients with low albumin levels before surgery, measures were taken to increase albumin levels, mainly using albumin supplementation and nutritional support. Only patients with albumin $>30 \mathrm{~g} / \mathrm{L}$ underwent surgery. Patients who had low albumin levels but underwent surgery because of corrected levels were classified as having low albumin levels for the analyses.

This study was approved by the ethics committee of the Harbin Medical Science University. The need for individual consent was waived by the committee because of the retrospective nature of the study.

2.2. Surgery and Perioperative Management. Routine blood and coagulation tests were monitored preoperatively, and patients with elevated amino transferase or bilirubin received liver protection therapy using $250 \mathrm{~mL}$ of $5 \%$ glucose solution with $120 \mathrm{mg}$ of glycyrrhizin, once per day, intravenously. Patients with serum bilirubin $>171 \mu \mathrm{mol} / \mathrm{L}$ (i.e., those with a suspicion of biliary function impairment and probably with abnormal absorption of vitamin $\mathrm{K}$ ) received intramuscular injections of vitamin K. Patients with serum bilirubin $>200 \mu \mathrm{mol} / \mathrm{L}$ underwent percutaneous transhepatic biliary drainage to prevent jaundice.

All patients underwent standard PD with reconstruction using the Child's approach. The approach to managing the pancreatic duct was determined according to the pancreatic texture and dilation of the pancreatic duct. Patients with pancreatic duct $\geq 3 \mathrm{~mm}$ and with a hard residual pancreas usually underwent mucosa-to-mucosa end-to-side pancreaticojejunostomy $(n=307)$. Patients with soft residual pancreas or normal pancreatic duct usually underwent endto-end or end-to-side pancreaticojejunostomy, in which the pancreatic stump was invaginated $2-3 \mathrm{~cm}$ and sutured using two interrupted layers $(n=116)$. In all patients, a drainage tube was placed in the pancreatic duct, with the distal end inserted into the jejunum to drain the pancreatic fluids into the distal jejunum or externally via the distal jejunum lumen to avoid contact of pancreatic and intestinal fluids on the anastomosis to reduce the risk of pancreatic fistula.

After surgery, patients were routinely fasted and received gastrointestinal decompression for 5-10 days, antibiotics, proton pump inhibitors, somatostatin, and other therapies as required. Somatostatin was given for 3-7 days according to the pancreas texture.

2.3. Evaluation of PPH. When $\mathrm{PPH}$ occurred, the patient routinely underwent abdominal CT examination. For patients with gastrointestinal bleeding, endoscopy was performed to identify the bleeding site and to treat the source of the bleeding using electrocoagulation or clipping. If endoscopy failed, then the patient underwent surgery. Patients with early abdominal bleeding (mild to moderate) first received nonsurgical treatment. Patients with severe abdominal bleeding went directly to laparotomy. Patients with late abdominal hemorrhage first received vascular embolization.

Bleeding was divided into abdominal $\mathrm{PPH}$ and digestive duct PPH. According to the criteria issued by the International Study Group of Pancreatic Surgery (ISGPS) [17], PPH was divided into early $(\leq 24 \mathrm{~h})$ and late $(>24 \mathrm{~h}) \mathrm{PPH}$. PPH was further divided into mild (grade A, no special intervention is required apart from symptomatic support) and severe $\mathrm{PPH}$ (grade $\mathrm{B}$, intervention is required; or grade $\mathrm{C}$, patient condition is critical) according to the severity [17]: (1) mild: hemoglobin reduction of $\leq 30 \mathrm{~g} / \mathrm{L}$ within $24 \mathrm{~h}$, with stable hemodynamics or maintainable circulation with adequate fluid replacement or (2) severe: hemoglobin reduction of $>30 \mathrm{~g} / \mathrm{L}$ within $24 \mathrm{~h}$, with significant hypovolemic shock, unrecoverable circulation with adequate fluid replacement, necessity of infusion of $>3 \mathrm{U}$ of packed red blood cells, and requirement for intervention or surgery.

Pancreatic fistula was defined according to the ISGPS [20], based on the amylase content of the abdominal drainage fluid being $>3$ times serum levels 3 days after PD. Pancreatic fistula was divided into grade A, B, or C: (1) grade A: transient, absence of symptoms, or increased amylase in drainage tube with nonsignificant imaging changes, and disappearance of drainage fluid within 3 weeks, especially at the first postoperative week; (2) grade B: fever, vomiting, aphagosis, abdominal pain and distension, and peripancreatic fluid in imaging; or (3) grade $\mathrm{C}$ : critical condition, unstable vital signs, more apparent abdominal symptoms and vital signs compared to grade $B$, significant peripancreatic fluid on imaging, requirement for reoperation, likelihood of complication with sepsis, multiple organ dysfunction syndrome, respiratory failure, or death.

Biliary fistula was defined as continuous drainage with abundant bile for more than 5 days. Postoperative abdominal infection was defined as persistent fever, increased leukocytosis, drainage of pus from the peritoneal drainage tube, and ascites on B-mode ultrasound or CT [24]. Finally, postoperative mortality was defined as death after PD and during hospitalization.

2.4. Treatment of PPH. Treatment of $\mathrm{PPH}$ was divided into nonsurgical and surgical treatments. The selection of the 
appropriate strategy was made by the surgeon. Nonsurgical treatment was preferred for patients with grades A and B $\mathrm{PPH}$ and included fasting, acid suppression, blood transfusion, somatostatin, hemostatic drugs, and other appropriate measures. Surgery was performed in patients with grade $\mathrm{C} \mathrm{PPH}$ and ineffective nonsurgical treatment and included exploratory laparotomy and hemostasis, total pancreatectomy, repair of pancreaticoenteric anastomosis, pancreaticobiliary diversion (PBD) (Roux-en-Y pancreatico-jejunum reanastomosis), pancreatic-gastric anastomosis, internal and external drainage of pancreatic duct, and abscess drainage. The surgical approach was based on localized injury caused by pancreatic leakage and the severity degree of abdominal infection. If the intraoperative assessment of abdominal infection caused by pancreatic leakage was severe, the risk of a second pancreaticojejunostomy was very high and anastomosis could not be performed again. Then, total pancreatectomy was selected.

Patients suffering from PPH after PD were followed up more intensively every four weeks for 3 months. The followup interval was one month. Follow-up was performed via telephone and/or visits to the outpatient clinic. Follow-up parameters included severe postsurgical complications (bile leakage, pancreatic leakage, abdominal infection, etc.), tumor recurrence, and metastases. In the presence of any complain from the patient or the family, the patient was seen at the outpatient clinic.

2.5. Data Collection. Risk factors of PPH were divided into three categories: (1) preoperative factors: age, gender, body mass index (BMI), hypertension, diabetes, coronary disease, smoking, alcohol, history of abdominal surgery, serum bilirubin, preoperative albumin level, and drainage; (2) intraoperative factors: surgical approach, intraoperative transfusion, use of anastomosis, revascularization, pancreatic duct diameter, and anastomotic approach; and (3) postoperative factors: pancreatic leakage, biliary fistula, abdominal infection, and use of somatostatin.

Total bilirubin was mainly used to detect the presence of liver disease or biliary tract abnormality. Normal total bilirubin levels range from 3.4 to $17.1 \mu \mathrm{mol} / \mathrm{L} ; 17.2-34.2 \mu \mathrm{mol} / \mathrm{L}$ was considered as recessive jaundice; $34.3-170 \mu \mathrm{mol} / \mathrm{L}$ was considered as mild jaundice; $171-340 \mu \mathrm{mol} / \mathrm{L}$ was considered as moderate jaundice; and $>340 \mu \mathrm{mol} / \mathrm{L}$ was considered as severe jaundice.

2.6. Statistical Analysis. Statistical analyses were performed using SPSS 19.0 (IBM, Armonk, NY, USA). Continuous data are presented as means \pm standard deviation and were analyzed using the Student $t$-test. Categorical data are presented as frequencies and were analyzed using the chisquare test or the Fisher exact test, as appropriate. Variables with significant associations in univariate analyses were included in multivariate analyses. Independent risk factors were identified using the logistic regression analysis (enter method). Associations are presented as odds ratios (OR) and $95 \%$ confidence intervals ( $95 \% \mathrm{CI}$ ). Two-sided $P$ values $<0.05$ were considered statistically significant.

\section{Results}

3.1. Characteristics of the Patients. There were 247 men and 176 women, aged $57.3 \pm 10.2$ (range $22-74$ ) years old. Malignant tumors or stromal tumors with malignant potential accounted for $88.4 \%(374 / 423)$ of the cases and benign diseases accounted for $11.6 \%$ (49/423). Postoperative pathological examinations confirmed 152 periampullary tumors (ampullary carcinoma, distal bile duct cancer, and duodenal papillary carcinoma of lower segment), 86 pancreatic ductal adenocarcinomas, 73 bile duct carcinomas, 31 duodenal adenocarcinomas, seven pancreatic neuroendocrine tumors, nine cystadenocarcinomas of the pancreas, seven malignant stromal tumors, six intraductal papillary mucinous neoplasms, three invasions by a gastrointestinal cancer, 12 chronic pancreatitides, eight pancreatic cystadenomas, six pancreatic solid pseudopapillary neoplasms, three duodenal papillary adenomas, three islet cell adenomas, one ectopic pancreas, and 16 other tumors.

3.2. Complications. Of the $423 \mathrm{PD}$ patients, the incidence of $\mathrm{PPH}$ was $9.9 \%$ (42/423). The postoperative incidence of pancreatic leakage, bile leakage, and abdominal infection was $23.2 \%$ (98/423), 5.9\% (25/423), and 4.7\% (20/423), respectively.

Among the 42 patients ( 33 male; 9 female) with PPH, 23 had early and 19 late $\mathrm{PPH}, 14$ arising from the digestive tract and 28 from elsewhere in the abdomen. There were 4 grade $\mathrm{A}$, 28 grade $\mathrm{B}$, and 10 grade $\mathrm{C} \mathrm{PPH}$. Most of the late abdominal $\mathrm{PPH}$ events were arterial $(57.9 \%, 11 / 19)$.

In this study, 19 patients suffered from late $\mathrm{PPH}$ and eight patients died (five after surgical treatment and three after nonsurgical treatment). All the 19 patients underwent angiography examination or gastrointestinal endoscopy at first. Among the 11 surviving patients, nine had abdominal bleeding. Among these nine patients, the bleeding site was detected by DSA in seven, and they all underwent hemostasis with embolization treatment. The exact bleeding site could not be identified in two patients. There were two cases of gastrointestinal tract bleeding. One underwent endoscopy and achieved hemostasis. The bleeding site in the other case could not be identified, but the bleeding resolved spontaneously.

Among the eight mortality cases, there were three patients who suffered from bleeding after embolization. Two patients whose bleeding sites were detected as the portal vein underwent surgery. Two other cases that underwent angiography and embolization died from organ failure. One patient diagnosed with gastrointestinal tract bleeding underwent endoscopy, but he died from organ failure.

3.3. Univariate Analyses of Risk Factors of PPH. Univariate analysis of preoperative factors for the occurrence of $\mathrm{PPH}$ (Table 1) showed that a history of abdominal surgery and low albumin levels were was significantly associated with early $\mathrm{PPH}$ and late PPH.

Similar analysis of intraoperative and postoperative factors (Table 2) demonstrates that revascularization was associated with early leakage while pancreatic fistula biliary fistula, 
TABLE 1: Univariate analyses of preoperative factors for early and late PPH.

\begin{tabular}{|c|c|c|c|c|c|c|}
\hline Variables & $\begin{array}{c}\text { Early PPH } \\
(n=23)\end{array}$ & $\begin{array}{c}\text { No PPH } \\
(n=381)\end{array}$ & $P$ & $\begin{array}{c}\text { Late PPH } \\
(n=19)\end{array}$ & $\begin{array}{c}\text { No PPH } \\
(n=381)\end{array}$ & $P$ \\
\hline $\begin{array}{l}\text { Preoperative serum } \\
\text { bilirubin }(\mu \mathrm{mol} / \mathrm{L})\end{array}$ & & & 0.071 & & & 0.394 \\
\hline$>171$ & 9 & 83 & & 6 & 83 & \\
\hline$\leq 171$ & 14 & 298 & & 13 & 298 & \\
\hline PBD & & & 0.738 & & & 0.717 \\
\hline Yes & 4 & 24 & & 2 & 24 & \\
\hline No & 7 & 53 & & 7 & 53 & \\
\hline $\begin{array}{l}\text { Previous abdominal } \\
\text { surgery }\end{array}$ & & & 0.001 & & & $<0.001$ \\
\hline Yes & 10 & 59 & & 9 & 59 & \\
\hline No & 13 & 322 & & 10 & 322 & \\
\hline $\begin{array}{l}\text { Worst preoperative } \\
\text { albumin levels }\end{array}$ & & & 0.001 & & & 0.002 \\
\hline Low $(<30 \mathrm{~g} / \mathrm{L})$ & 11 & 64 & & 8 & 64 & \\
\hline Normal (>30 g/L) & 12 & 317 & & 11 & 317 & \\
\hline
\end{tabular}

PPH: postpancreatectomy hemorrhage; PBD: pancreaticobiliary diversion.

TABLE 2: Univariate analyses of intraoperative and postoperative factors for early and late PPH.

\begin{tabular}{|c|c|c|c|c|c|c|}
\hline Variables & $\begin{array}{c}\text { Early PPH } \\
(n=23)\end{array}$ & $\begin{array}{c}\text { No PPH } \\
(n=381)\end{array}$ & $P$ & $\begin{array}{c}\text { Late PPH } \\
(n=19)\end{array}$ & $\begin{array}{c}\text { No PPH } \\
(n=381)\end{array}$ & $P$ \\
\hline Anastomosis type & & & 0.223 & & & 0.181 \\
\hline Nonmucosa to mucosa & 9 & 99 & & 8 & 99 & \\
\hline Mucosa to mucosa & 14 & 282 & & 11 & 282 & \\
\hline $\begin{array}{l}\text { Postoperative pancreatic } \\
\text { fistula }\end{array}$ & & & $>0.99$ & & & 0.011 \\
\hline Yes & 0 & 88 & & 10 & 88 & \\
\hline No & 0 & 293 & & 9 & 293 & \\
\hline Preoperative biliary fistula & & & $>0.99$ & & & 0.024 \\
\hline Yes & 0 & 21 & & 4 & 21 & \\
\hline No & 0 & 360 & & 15 & 360 & \\
\hline $\begin{array}{l}\text { Postoperative abdominal } \\
\text { abscess }\end{array}$ & & & $>0.99$ & & & 0.011 \\
\hline Yes & 0 & 16 & & 4 & 16 & \\
\hline No & 0 & 365 & & 15 & 365 & \\
\hline Vascular reconstruction & & & 0.018 & & & 0.047 \\
\hline Yes & 4 & 15 & & 3 & 15 & \\
\hline No & 19 & 366 & & 16 & 366 & \\
\hline $\begin{array}{l}\text { Intraoperative pancreatic } \\
\text { duct diameter }\end{array}$ & & & 0.654 & & & 0.854 \\
\hline$\geq 3 \mathrm{~mm}$ & 10 & 135 & & 12 & 254 & \\
\hline$<3 \mathrm{~mm}$ & 13 & 265 & & 7 & 127 & \\
\hline
\end{tabular}

PPH: postpancreatectomy hemorrhage; PPPD: pylorus-preserving pancreaticoduodenectomy; PD: pancreaticoduodenectomy.

abdominal abscess, and revascularization were associated with late $\mathrm{PPH}$.

3.4. Multivariate Analyses of Risk Factors of PPH. Multivariate analysis (Table 3 ) demonstrated that revascularization, past history of abdominal surgery, and preoperative albumin levels were independently associated with early PPH.

The independent risk factors for late $\mathrm{PPH}$ (Table 4) included postoperative pancreatic fistula postoperative bile fistula postoperative abdominal abscess revascularization, 
TABLE 3: Multivariate analysis of risk factors of early PPH.

\begin{tabular}{lcccc}
\hline \multirow{2}{*}{ Variables } & \multirow{2}{*}{ OR } & \multicolumn{2}{c}{$95 \%$ CI } \\
& & & Lower & Upper \\
\hline Vascular reconstruction & 0.005 & 6.786 & 1.785 & 25.792 \\
History of abdominal surgery & 0.001 & 5.009 & 1.968 & 12.749 \\
Preoperative albumin level & 0.001 & 4.863 & 1.962 & 12.005 \\
\hline
\end{tabular}

PPH: postpancreatectomy hemorrhage; OR: odds ratio; $95 \% \mathrm{CI}$ : $95 \%$ confidence interval.

TABLE 4: Multivariate analysis of risk factors of late PPH.

\begin{tabular}{lcccc}
\hline \multirow{2}{*}{ Variables } & \multirow{2}{*}{ OR } & \multicolumn{2}{c}{$95 \%$ CI } \\
& & & Upper & Lower \\
\hline $\begin{array}{l}\text { Preoperative } \\
\text { pancreatic leakage }\end{array}$ & 0.005 & 4.696 & 1.605 & 13.740 \\
$\begin{array}{l}\text { Postoperative bile } \\
\text { leakage }\end{array}$ & 0.009 & 6.096 & 1.575 & 23.598 \\
$\begin{array}{l}\text { Postoperative } \\
\text { abdominal infection }\end{array}$ & 0.036 & 4.605 & 1.108 & 19.144 \\
$\begin{array}{l}\text { Vascular } \\
\text { reconstruction }\end{array}$ & 0.007 & 9.943 & 1.900 & 52.042 \\
$\begin{array}{l}\text { Past history of } \\
\text { abdominal surgery }\end{array}$ & $<0.001$ & 8.790 & 2.779 & 27.806 \\
$\begin{array}{l}\text { Preoperative albumin } \\
\text { level }\end{array}$ & 0.002 & 5.563 & 1.845 & 16.776 \\
\hline
\end{tabular}

PPH: postpancreatectomy hemorrhage; OR: odds ratio; 95\% CI: 95\% confidence interval.

history of abdominal surgery, and preoperative albumin levels.

3.5. Mortality. The overall mortality from PPH (Table 5) was 2.1\% (9/423). All patients with late PPH underwent DSA before surgery, while patients with early PPH did not undergo DSA.

\section{Discussion}

The incidence of PPH of $9.9 \%$ in this study is slightly higher than the $5.7-8.8 \%$ reported previously $[1,13]$. A number of factors could be involved in this difference. In the early period of this study, there was no permanent team for pancreatic surgery, resulting in a low degree of specialization and a lack of multidisciplinary cooperation. In the last 2 years of the study period, the incidence of PPH decreased to $6.3 \%$, suggesting that establishing a professional team dedicated to pancreatic surgery can significantly reduce iatrogenic bleeding and the occurrence of $\mathrm{PPH}$. Our mortality rate for PPH of $21.4 \%$ is consistent with the $11-47 \%$ previously reported $[1,14]$.

This study showed that vascular reconstruction and history of previous abdominal surgery were independent risk factors of early $\mathrm{PPH}$, which support the view proposed by the ISGPS that early surgery should be considered for early PPH [17]. This study also found that bleeding from residual uncinate process was another important cause of early PPH [25] and accounted for $8.7 \%(2 / 23)$ of the early PPH cases.
The uncinate process is located deeply with a number of arterial branches within it; therefore, mass ligation is prone to incomplete hemostasis, perhaps contributing to early PPH. In addition, necrosis of the residual uncinate process may cause late PPH. Total resection of the uncinate process would represent a good method of preventing hemorrhage from any residual pancreatic tissue. The authors adopted the method of resecting the tissue to the right side of the superior mesenteric artery sheath, including the uncinate process, resulting in elimination of residual postoperative bleeding of the uncinate process. DSA examination and TAE can be used in patients with early PPH in which nonsurgical treatment is ineffective [26]. CTA could help the diagnosis of delayed arterial hemorrhage with a positive rate above 95\% [27]. Meanwhile, TAE can be applied simultaneously if the bleeding parts can be accurately identified [28].

Postoperative pancreatic fistula and abdominal infection are independent risk factors of late PPH. Data from the ISGPS also revealed that pancreatic fistulae, abdominal infection, vascular corrosion by digestive juices, and other postoperative complications were the main reasons for late $\mathrm{PPH}$. Late PPH is also known as pancreatic fistula-related bleeding. In the 19 cases with PPH in this study, 94.7\% (18/19) also showed pancreatic fistula, and 26.5\% (5/19) also had abdominal infection. Among the nine deceased patients, cases of late PPH were always accompanied by pancreatic leakage and this rate was higher than in previous studies [29]. It might be because some patients might suffer from missed or occult pancreatic fistula or collections. Early diagnosis of pancreatic fistula relies on close observation of the abdominal drain including color and amount of abdominal drainage fluid. Early determination of amylase after surgery is vital for early diagnosis in patients whose recovery is not smooth. Patients with poor drainage and symptoms of intraabdominal abscess/collection should undergo ultrasoundor CT-guided puncture as early as possible to avoid the accumulation of pancreatic juice and abscesses and corrosion of vessels [30, 31].

In this study, most of the late abdominal PPH events were arterial $(57.9 \%, 11 / 19)$. Normally, a small amount of bleeding will occur $6 \mathrm{~h}$ to $10 \mathrm{~d}$ before late PPH, which is called "sentinel bleeding" [32] and occurs in $45 \%$ of the patients with late PPH. This indicates that attention should be paid to the sentinel bleeding in predicting late $\mathrm{PPH}$, and effective measure should then be taken to prevent PPH. It has been suggested that angiography should be immediately conducted in patients with sentinel bleeding in order to provide early treatments [33].

Five patients treated with preoperative DSA or TAE treatment died after surgery because hemostasis could not be achieved. Late PPH is associated with more unstable hemodynamics. Bleeding is usually more important and treatment rarely achieves good results. Based on our experience, we summarized the clinical pathway for the treatment of $\mathrm{PPH}$ in Figure 1. The combined use of medical therapy (such as somatostatin), angiography, and laparoscopy based on this algorithm could have contributed to the relatively low mortality rate observed in the present study. Of course, the patients have to be carefully selected and the absence of 


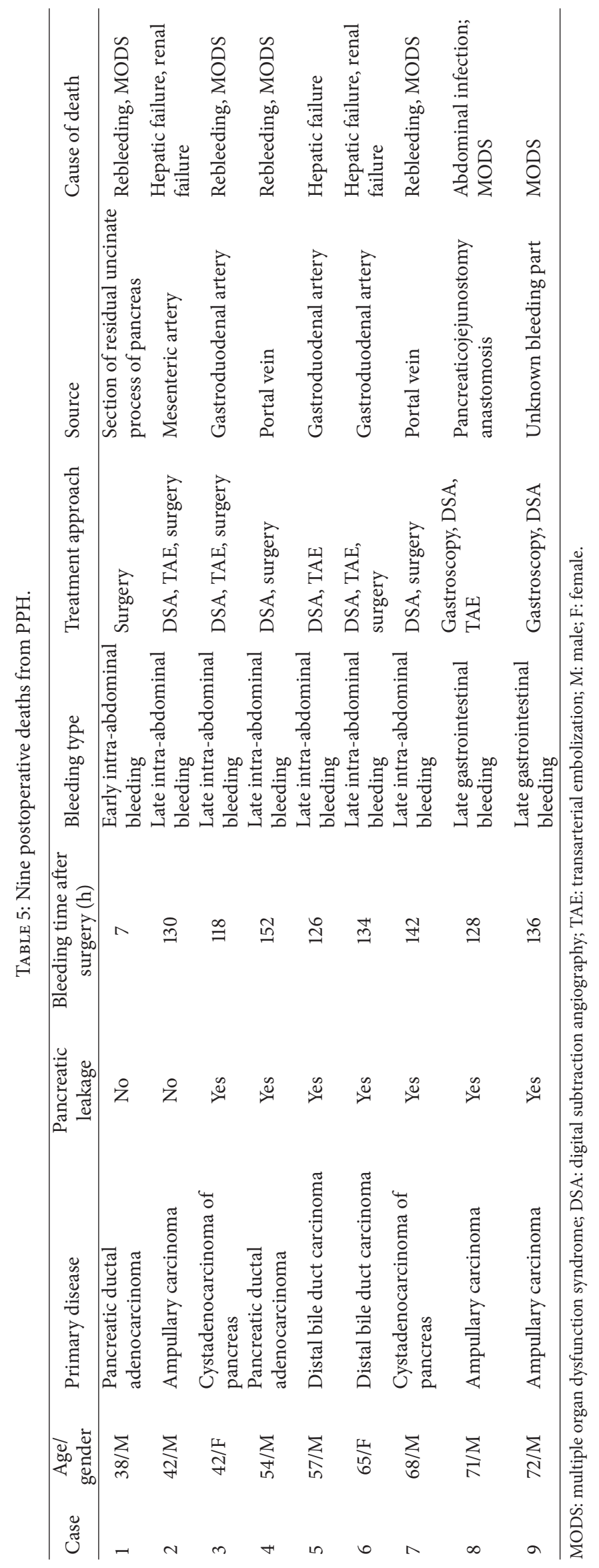




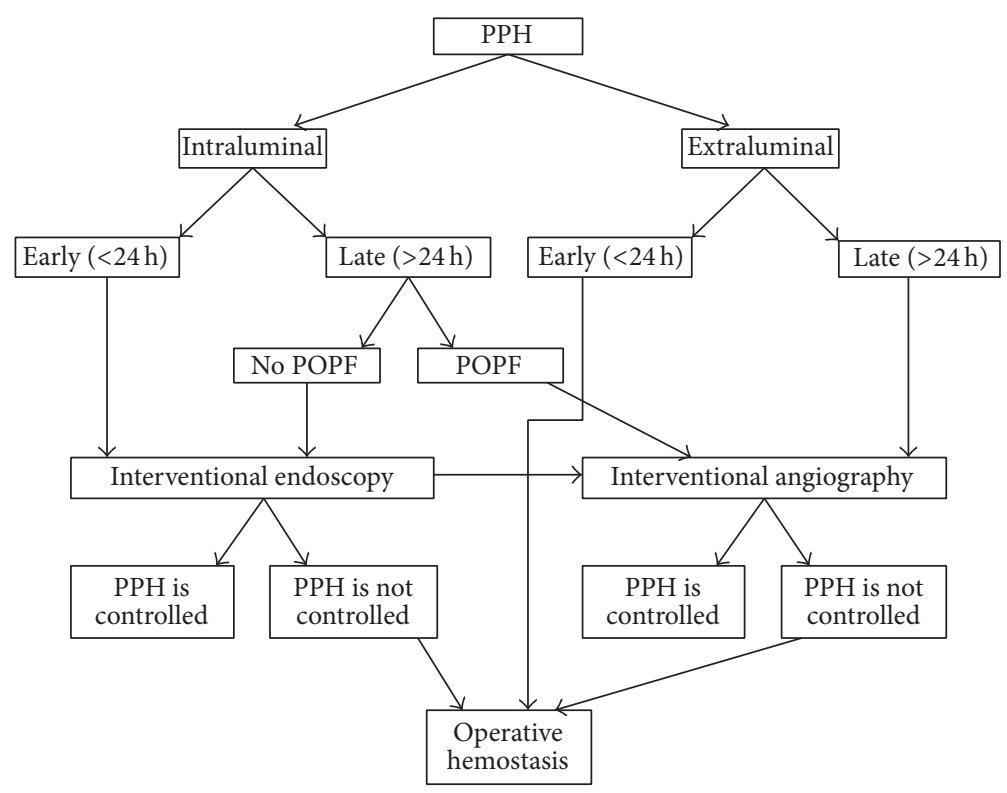

FIGURE 1: Suggested management algorithm of postpancreatectomy hemorrhage (PPH). POPF: postoperative pancreatic fistula.

metastasis has to have been proven before any surgery in order to avoid unnecessary surgery and risks. An Italian study of 544 hospitals showed that $9 \%$ of pancreatic resections were performed in patients with distant metastases [34], which should be avoided. Nevertheless, other techniques should be explored to further lower this mortality rate, such as endovascular techniques [35].

The present study found that the independent risk factors that correlated with early/late $\mathrm{PPH}$ included history of abdominal surgery and preoperative albumin level. Indeed, surgery may more difficult in patients who have a history of abdominal surgery because of the eventual presence of scars, fibrosis, adhesions, clips, and changed anatomy. Postoperative scar tissue is rich in blood vessels and it is easy to make them bleed during surgery and hemostasis is difficult because of the absence of major blood vessels. These factors could lead to a higher incidence of PPH.

An excessively low preoperative serum albumin levels indicate poor liver function and malnutrition and often indicate a poor tolerance to surgery and unfavorable anastomosis healing, prone to ascites and pancreatic fistula, which were also the main risk factors of PPH. This is supported by a previous study that showed that the nutritional risk index was associated with the risk of PPH [31].

This study suffers from some limitations. The sample size was limited, preventing the observation of some possible associations. In addition, it was from a single institution with changing practice over time. Additional multicenter studies should be performed to confirm these results.

\section{Conclusions}

In conclusion, results suggest that $\mathrm{PPH}$ could be prevented by improving the preoperative nutrition of patients, accurate
$\mathrm{PD}$, protection of blood vessels, proper hemostasis, and prevention and treatment of pancreatic leakage and abdominal infection.

\section{Competing Interests}

The authors declare that there is no conflict of interests regarding the publication of this paper.

\section{Authors' Contributions}

Feng Gao and Jianguo Li contributed equally to this work and should be considered co-first authors.

\section{Acknowledgments}

The authors acknowledge the help of Professor Wu Dequan and Professor Zeng Zhaolin. This study was supported by the Fund for Science and Technology Research Project, Bureau of science and technology, Harbin (Grant no. 2015RAQYJ103) and the Fund for Science and Technology Research Project, Department of Education, Heilongjiang Province (Grant no. 12521234).

\section{References}

[1] J. Feng, Y.-L. Chen, J.-H. Dong, M.-Y. Chen, S.-W. Cai, and Z.-Q. Huang, "Post-pancreaticoduodenectomy hemorrhage: risk factors, managements and outcomes," Hepatobiliary and Pancreatic Diseases International, vol. 13, no. 5, pp. 513-522, 2014.

[2] C. J. Yeo, J. L. Cameron, T. A. Sohn et al., "Six hundred fifty consecutive pancreaticoduodenectomies in the 1990s: pathology, complications, and outcomes," Annals of Surgery, vol. 226, no. 3, pp. 248-260, 1997. 
[3] B. W. Miedema, M. G. Sarr, J. A. Van Heerden et al., "Complications following pancreaticoduodenectomy: current management," Archives of Surgery, vol. 127, no. 8, pp. 945-950, 1992.

[4] J. H. T. Balcom IV, D. W. Rattner, A. L. Warshaw, Y. Chang, and C. Fernandez-del Castillo, "Ten-year experience with 733 pancreatic resections: changing indications, older patients, and decreasing length of hospitalization," Archives of Surgery, vol. 136, no. 4, pp. 391-398, 2001.

[5] E. F. Yekebas, L. Wolfram, G. Cataldegirmen et al., "Postpancreatectomy hemorrhage: diagnosis and treatment: an analysis in 1669 consecutive pancreatic resections," Annals of Surgery, vol. 246, no. 2, pp. 269-280, 2007.

[6] O. Turrini, V. Moutardier, J. Guiramand et al., "Hemorrhage after duodenopancreatectomy: impact of neoadjuvant radiochemotherapy and experience with sentinel bleeding," World Journal of Surgery, vol. 29, no. 2, pp. 212-216, 2005.

[7] H.-K. Wei, S.-E. Wang, Y.-M. Shyr et al., "Risk factors for postpancreaticoduodenectomy bleeding and finding an innovative approach to treatment," Digestive Surgery, vol. 26, no. 4, pp. 297305, 2009.

[8] B. Rumstadt, M. Schwab, P. Korth, M. Samman, and M. Trede, "Hemorrhage after pancreatoduodenectomy," Annals of Surgery, vol. 227, no. 2, pp. 236-241, 1998.

[9] Y.-S. Yoon, S.-W. Kim, K.-H. Her et al., "Management of Postoperative Hemorrhage after Pancreatoduodenectomy," HepatoGastroenterology, vol. 50, no. 54, pp. 2208-2212, 2003.

[10] S. H. Choi, H. J. Moon, J. S. Heo, J. W. Joh, and Y. I. Kim, "Delayed hemorrhage after pancreaticoduodenectomy," Journal of the American College of Surgeons, vol. 199, no. 2, pp. 186-191, 2004.

[11] P. Balachandran, S. S. Sikora, R. V. Raghavendra Rao, A. Kumar, R. Saxena, and V. K. Kapoor, "Haemorrhagic complications of pancreaticoduodenectomy," ANZ Journal of Surgery, vol. 74, no. 11, pp. 945-950, 2004.

[12] F. Makowiec, H. Riediger, W. Euringer, M. Uhl, U. T. Hopt, and U. Adam, "Management of delayed visceral arterial bleeding after pancreatic head resection," Journal of Gastrointestinal Surgery, vol. 9, no. 9, pp. 1293-1299, 2005.

[13] I. Koukoutsis, R. Bellagamba, G. Morris-Stiff et al., "Haemorrhage following pancreaticoduodenectomy: risk factors and the importance of sentinel bleed," Digestive Surgery, vol. 23, no. 4, pp. 224-228, 2006

[14] T. Blanc, A. Cortes, D. Goere et al., "Hemorrhage after pancreaticoduodenectomy: when is surgery still indicated?" The American Journal of Surgery, vol. 194, no. 1, pp. 3-9, 2007.

[15] C. Liu, Y.-H. Qiu, X.-J. Luo et al., “Treatment of massive pancreaticojejunal anastomotic hemorrhage after pancreatoduodenectomy," World Journal of Gastroenterology, vol. 15, no. 13, pp. 1625-1629, 2009.

[16] M. J. Mañas-Gómez, R. Rodríguez-Revuelto, J. Balsells-Valls et al., "Post-pancreaticoduodenectomy hemorrhage. Incidence, diagnosis, and treatment," World Journal of Surgery, vol. 35, no. 11, pp. 2543-2548, 2011.

[17] M. N. Wente, J. A. Veit, C. Bassi et al., "Postpancreatectomy hemorrhage (PPH): an International Study Group of Pancreatic Surgery (ISGPS) definition," Surgery, vol. 142, no. 1, pp. 20-25, 2007.

[18] D. Roulin, Y. Cerantola, N. Demartines, and M. Schäfer, "Systematic review of delayed postoperative hemorrhage after pancreatic resection," Journal of Gastrointestinal Surgery, vol. 15, no. 6, pp. 1055-1062, 2011.
[19] F. Miura, T. Asano, H. Amano et al., "Management of postoperative arterial hemorrhage after pancreato-biliary surgery according to the site of bleeding: re-laparotomy or interventional radiology," Journal of Hepato-Biliary-Pancreatic Surgery, vol. 16, no. 1, pp. 56-63, 2009.

[20] C. Bassi, C. Dervenis, G. Butturini et al., "Postoperative pancreatic fistula: an international study group (ISGPF) definition," Surgery, vol. 138, no. 1, pp. 8-13, 2005.

[21] E. C. Ellison, "Evidence-based management of hemorrhage after pancreaticoduodenectomy," American Journal of Surgery, vol. 194, no. 1, pp. 10-12, 2007.

[22] R. B. Jagad, M. Koshariya, J. Kawamoto, G. S. Chude, R. V. Neeraj, and N. J. Lygidakis, "Postoperative hemorrhage after major pancreatobiliary surgery: an update," Hepato-Gastroenterology, vol. 55, no. 82-83, pp. 729-737, 2008.

[23] Y.-W. Tien, P.-H. Lee, C.-Y. Yang, M.-C. Ho, and Y.-F. Chiu, "Risk factors of massive bleeding related to pancreatic leak after pancreaticoduodenectomy," Journal of the American College of Surgeons, vol. 201, no. 4, pp. 554-559, 2005.

[24] M. Kawai, M. Tani, S. Hirono, S. Ina, M. Miyazawa, and H. Yamaue, "How do we predict the clinically relevant pancreatic fistula after pancreaticoduodenectomy?-an analysis in 244 consecutive patients," World Journal of Surgery, vol. 33, no. 12, pp. 2670-2678, 2009.

[25] Y.-I. Yamashita, A. Taketomi, K. Fukuzawa et al., "Risk factors for and management of delayed intraperitoneal hemorrhage after pancreatic and biliary surgery," American Journal of Surgery, vol. 193, no. 4, pp. 454-459, 2007.

[26] J. Zhang, X. Zhu, H. Chen et al., "Management of delayed postpancreaticoduodenectomy arterial bleeding: interventional radiological treatment First," Pancreatology, vol. 11, no. 5, pp. 455-463, 2011.

[27] A. E. Chua and L. J. Ridley, "Diagnostic accuracy of CT angiography in acute gastrointestinal bleeding," Journal of Medical Imaging and Radiation Oncology, vol. 52, no. 4, pp. 333-338, 2008.

[28] U. F. Wellner, B. Kulemann, H. Lapshyn et al., "Postpancreatectomy hemorrhage-incidence, treatment, and risk factors in over 1,000 pancreatic resections," Journal of Gastrointestinal Surgery, vol. 18, no. 3, pp. 464-475, 2014.

[29] E. Benzoni, E. Saccomano, A. Zompicchiatti et al., "The role of pancreatic leakage on rising of postoperative complications following pancreatic surgery," Journal of Surgical Research, vol. 149, no. 2, pp. 272-277, 2008.

[30] T. A. Sohn, C. J. Yeo, J. L. Cameron et al., "Pancreaticoduodenectomy: role of interventional radiologists in managing patients and complications," Journal of Gastrointestinal Surgery, vol. 7, no. 2, pp. 209-219, 2003.

[31] B. Darnis, R. Lebeau, X. Chopin-Laly, and M. Adham, "Postpancreatectomy hemorrhage $(\mathrm{PPH})$ : predictors and management from a prospective database," Langenbeck's Archives of Surgery, vol. 398, no. 3, pp. 441-448, 2013.

[32] J. T. Brodsky and A. D. M. Turnbull, "Arterial hemorrhage after pancreatoduodenectomy. The 'sentinel bleed"' Archives of Surgery, vol. 126, no. 8, pp. 1037-1040, 1991.

[33] S. M. M. de Castro, K. F. D. Kuhlmann, O. R. C. Busch et al., "Delayed massive hemorrhage after pancreatic and biliary surgery: embolization or surgery?" Annals of Surgery, vol. 241, no. 1, pp. 85-91, 2005.

[34] G. Balzano, G. Capretti, G. Callea, E. Cantù, F. Carle, and R. Pezzilli, "Overuse of surgery in patients with pancreatic cancer. 
A nationwide analysis in Italy," $H P B$, vol. 18, no. 5, pp. 470-478, 2016.

[35] K. Asai, V. Zaydfudim, M. Truty et al., "Management of a delayed post-pancreatoduodenectomy haemorrhage using endovascular techniques," $H P B$, vol. 17, no. 10, pp. 902-908, 2015. 


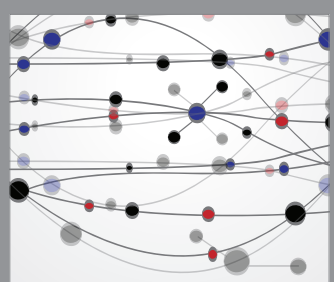

The Scientific World Journal
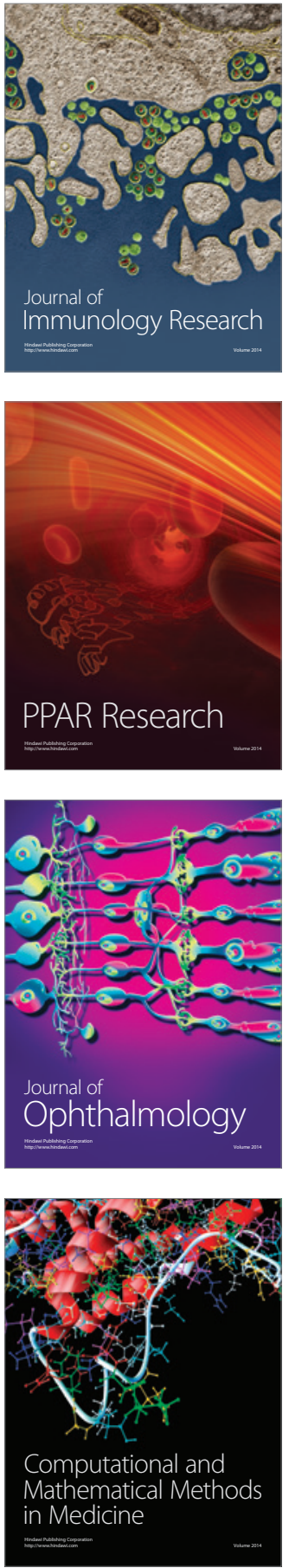

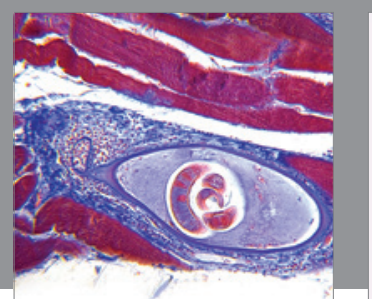

Gastroenterology Research and Practice

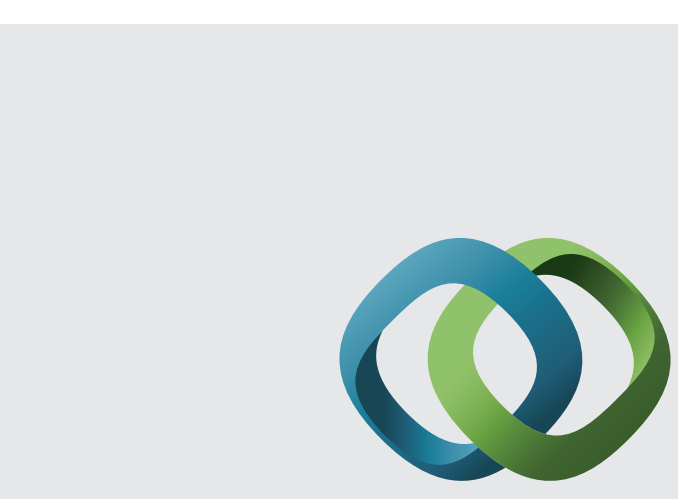

\section{Hindawi}

Submit your manuscripts at

http://www.hindawi.com
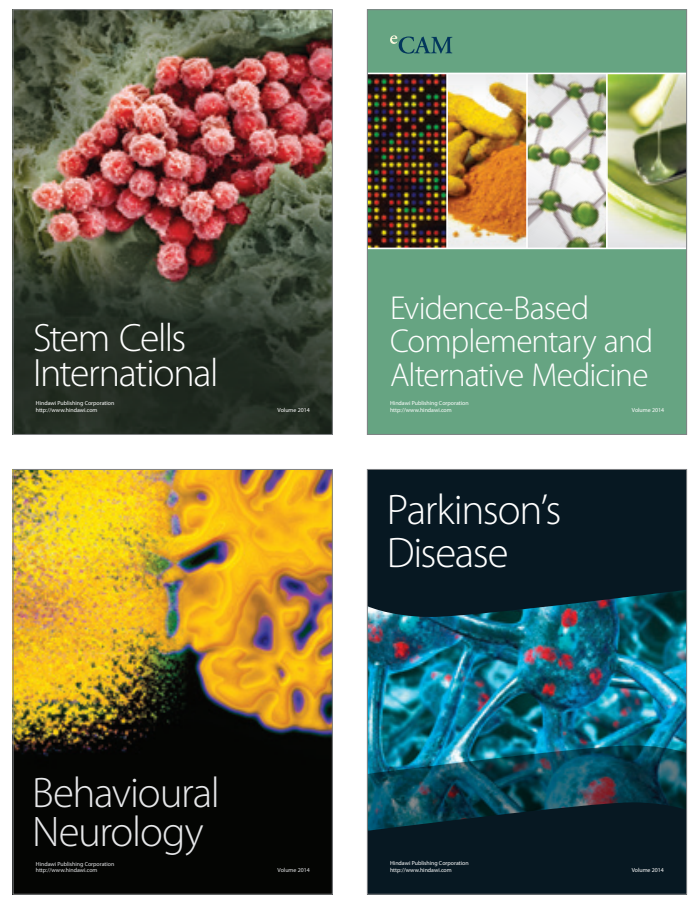
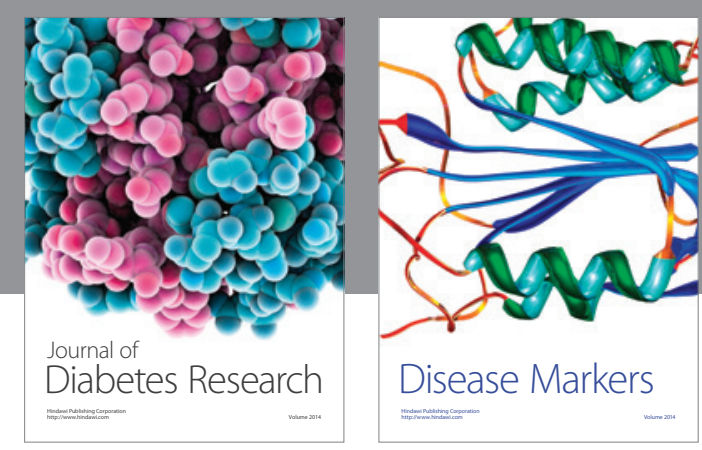

Disease Markers
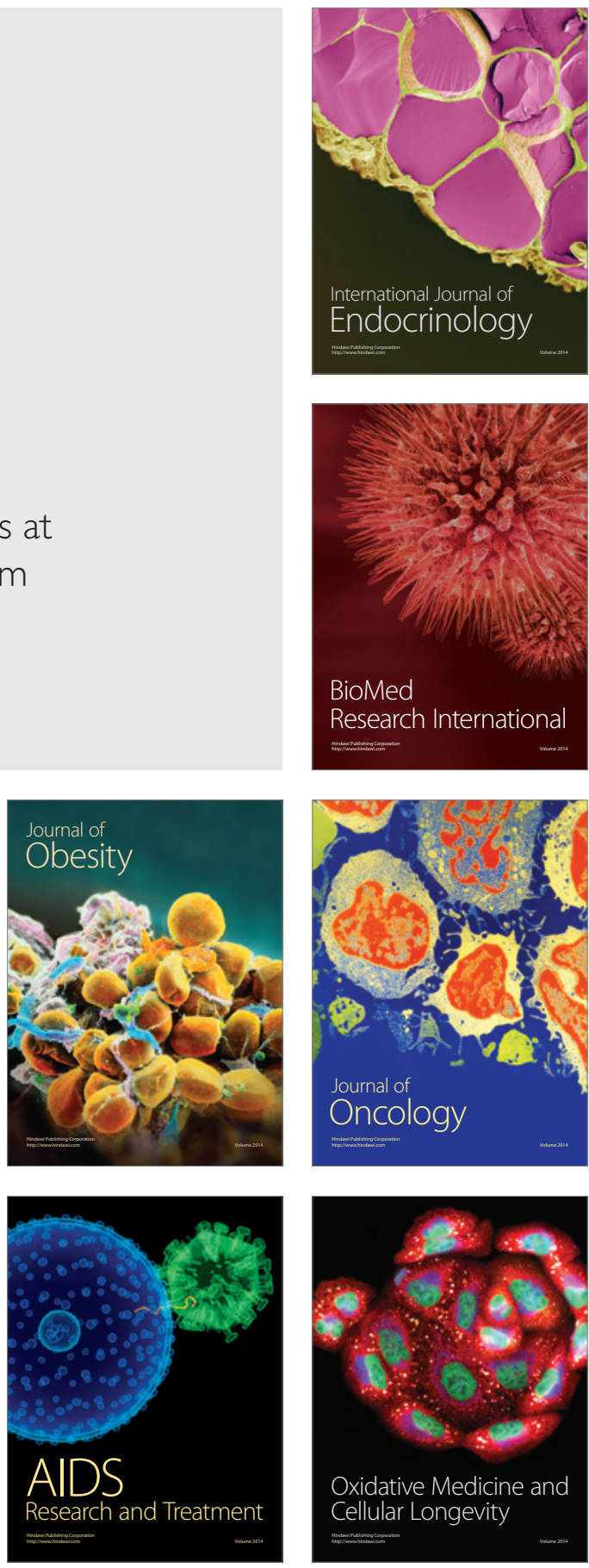